\title{
Mechanism and kinetics of thermal degradation of insulating materials developed from cellulose fiber and fire retardants
}

\author{
Chao Zheng ${ }^{1}$ (1) $\cdot$ Dongfang $\mathrm{Li}^{1} \cdot$ Monica Ek ${ }^{1}$
}

Received: 4 May 2018 / Accepted: 15 July 2018/Published online: 25 July 2018

(C) The Author(s) 2018

\begin{abstract}
The mechanism and kinetics of thermal degradation of materials developed from cellulose fiber and synergetic fire retardant or expandable graphite have been investigated using thermogravimetric analysis. The model-free methods such as KissingerAkahira-Sunose (KAS), Friedman, and Flynn-Wall-Ozawa (FWO) were applied to measure apparent activation energy $\left(E_{\alpha}\right)$. The increased $E_{\alpha}$ indicated a greater thermal stability because of the formation of a thermally stable char, and the decreased $E_{\alpha}$ after the increasing region related to the catalytic reaction of the fire retardants, which revealed that the pyrolysis of fire retardant-containing cellulosic materials through more complex and multi-step kinetics. The Friedman method can be considered as the best method to evaluate the $E_{\alpha}$ of fire-retarded cellulose thermal insulation compared with the KAS and FWO methods. A master-plots method such as the Criado method was used to determine the possible degradation mechanisms. The degradation of cellulose thermal insulation without a fire retardant is governed by a $\mathrm{D} 3$ diffusion process when the conversion value is below 0.6 , but the materials containing synergetic fire retardant and expandable graphite fire retardant may have a complicated reaction mechanism that fits several proposed theoretical models in different conversion ranges. Gases released during the thermal degradation were identified by pyrolysis-gas chromatography/mass spectrometry. Fire retardants could catalyze the dehydration of cellulosic thermal insulating materials at a lower temperature and facilitate the generation of furfural and levoglucosenone, thus promoting the formation of char. These results provide useful information to understand the pyrolysis and fire retardancy mechanism of fire-retarded cellulose thermal insulation.
\end{abstract}

Keywords Thermal degradation · Thermal kinetics · Fire retardant - Cellulose fiber · Thermal insulating

$\begin{array}{ll}\text { List of symbols and abbreviations } \\ a & \text { Conversion degree } \\ \beta & \text { Heating rate }\left(\mathrm{K} \mathrm{min}^{-1}\right) \\ f(a) & \begin{array}{l}\text { Function of the degradation reaction } \\ \text { mechanism }\end{array} \\ g(a) & \begin{array}{l}\text { The integral function of the degradation } \\ \text { reaction mechanism }\end{array} \\ k & \text { Rate constant associated with the temperature } \\ t & \text { Time (s) } \\ A & \text { Pre-exponential factor }\left(\mathrm{min}^{-1}\right)\end{array}$

Electronic supplementary material The online version of this article (https://doi.org/10.1007/s10973-018-7564-5) contains supplementary material, which is available to authorized users.

Chao Zheng

chaozh@kth.se

1 Department of Fiber and Polymer Technology, KTH Royal Institute of Technology, Teknikringen 56-58, 10044 Stockholm, Sweden

\begin{tabular}{|c|c|}
\hline APP & Ammonium polyphosphate \\
\hline $\mathrm{ATH}$ & Aluminum hydroxide \\
\hline$E_{\mathrm{a}}$ & Apparent activation energy $\left(\mathrm{kJ} \mathrm{mol}^{-1}\right)$ \\
\hline EGIM & $\begin{array}{l}\text { Expandable graphite fire-retardant insulating } \\
\text { material }\end{array}$ \\
\hline FWO & Flynn-Wall-Ozawa \\
\hline KAS & Kissinger-Akahira-Sunose \\
\hline $\mathrm{Py}-\mathrm{GC} /$ & Pyrolysis-gas chromatography-mass \\
\hline MS & spectroscopy \\
\hline$R$ & Gas constant $\left(8.314 \mathrm{~J} \mathrm{~K}^{-1} \mathrm{~mol}^{-1}\right)$ \\
\hline SYIM & Synergetic fire retardant insulating material \\
\hline$T$ & Absolute temperature $(\mathrm{K})$ \\
\hline TG & Thermogravimetry \\
\hline
\end{tabular}

\section{Introduction}

Cellulose fiber-based thermal insulating materials could be promising alternatives to the petroleum-based materials to meet the increase in demand for eco-friendly and 
sustainable building materials [1]. To improve the fire safety of cellulose fiber-based thermal insulating materials used in buildings, different types of fire retardants have been used, such as expandable graphite and a synergetic fire retardant that have low toxicity and low smoke production during combustion. Our previous study has shown that cellulose fiber-based thermal insulation developed from formulations containing cellulose fibers and 10-30\% of two types of fire retardants were subjected to the reaction-to-fire tests, when $20 \%$ expandable graphite or $25 \%$ synergetic fire retardant was added to the formula, the thermal insulation materials can meet the requirements of fire class E according to the European standard [2, 3], and show an enhanced fire retardancy [4]. However, the effects of these fire retardants on the thermal degradation kinetics and pyrolysis products of cellulosic thermal insulating materials have yet to be investigated. And few publications focused on kinetics and mechanism of thermal degradation of cellulosic insulating materials developed from mechanical pulp fiber and fire retardants. Therefore, it is important to obtain a detailed information about the pyrolysis of cellulosic insulating materials with or without fire retardants to get a more in-depth understanding of the combustion process.

To elucidate the flame-retarding process, the thermal decomposition of the flame-retardant material can be quantitatively described by the thermal degradation kinetics. The kinetic parameters such as apparent activation energy $\left(E_{\mathrm{a}}\right)$ and pre-exponential factor $(A)$ can be calculated using the model-free or isoconversional methods such as Kissinger-Akahira-Sunose (KAS) [5-7], the Friedman [8], the Flynn-Wall-Ozawa (FWO) [9, 10], and the modelfitting method such as Coats-Redfern method [11]. Among the different methods used to evaluate the kinetic parameters, the Coats-Redfern method could be less suitable for determination of kinetic parameters due to the uncertain reaction models [12].

It is difficult to model the material behavior when the material is exposed to a fire due to the complex combination of fluid dynamics, combustion, heat and mass transfer, and kinetics [13]. Many studies on the contributions of fire retardant have concluded that a fire retardant can catalyze the cellulose degradation and improve the generation of char that reduces the heat and mass transfer [14-16]. The thermal stability, decomposition rate, char-forming rate, and char yield of the thermal insulating materials also affect the fire retardancy [17, 18]. To understand the mechanism of fire retardancy, the master-plots method such as Criado method [19] can be used to predict the reaction mechanism $[f(\alpha)]$ or the possible kinetic models, e.g., experimental data are transformed into master plots, then the master plots are compared with the theoretical models to identify the potential reaction mechanism during the pyrolysis process [20]. Besides, pyrolysis-gas chromatography/mass spectrometry (Py-GC/MS) is an effective method to study the degradation products of cellulose fiber-based thermal insulating materials and is helpful to explain and confirm the fire retardancy mechanism.

The objectives of the present study were to determine the kinetic parameters and examine if the $E_{\alpha}$ is constant with the degree of conversion and the suitability of the proposed methods. In addition, thermal degradation, fire retardancy mechanisms and gaseous products emitted during the degradation of thermally insulating materials produced from mechanical pulp fiber, expandable graphite or a synergetic intumescent fire retardant need to be determined using the Thermogravimetry (TG) and $\mathrm{Py}-\mathrm{GC} / \mathrm{MS}$ to further understand the fire retardancy reactions.

In the present study, model-free methods such as the KAS, Friedman, and FWO methods were used to compare the difference of the activation energy of cellulosic thermal insulating materials with or without fire retardants. Expandable graphite and a synergetic intumescent fire retardant were selected to study their effects on the mechanical pulp fiber due to their wide use in the market. Master-plots method such as the Criado method was applied to identify the possible reaction models of cellulosic thermal insulating materials with and without fire retardant. The quantity and composition of volatile products from the decomposition and pyrolysis of the flame-retardant cellulose fiber-based thermal insulating materials were determined by Py-GC/MS to get a better understanding of fire retardancy mechanism.

\section{Materials and methods}

\section{Materials}

Bleached chemi-thermomechanical pulp (CTMP) was provided by Rottneros (Söderhamn, Sweden). The chemical composition of the CTMP is listed in Table 1. Sodium dodecyl sulfate $(\geq 99.0 \%)$ was purchased from SigmaAldrich (Stockholm, Sweden). Commercial expandable graphite was provided by GrafTech (USA). A synergetic intumescent fire retardant (50\% ammonium sulfate, $10 \%$ ammonium polyphosphate, and $40 \%$ aluminum hydroxide) was obtained from a local supplier.

\section{Sample preparation}

A suspension of CTMP (45 $\mathrm{g}$ of pulp fibers were suspended in $1 \mathrm{~L}$ of water) was mixed with $0.3 \mathrm{~g}$ of sodium dodecyl sulfate foaming agent and either $20 \%$ of expandable graphite or $25 \%$ of a synergetic intumescent fire 
Table 1 Chemical composition of CTMP

\begin{tabular}{llllllllll}
\hline Extractives/\% & Moisture/\% & Ash/\% & Lignin/\% & Arabinose/\% & Galactose/\% & Glucose/\% & Xylose/\% & Rhamnose/\% & Mannose/\% \\
\hline $1.3 \pm 0$ & $8.5 \pm 0$ & $1.5 \pm 0$ & $26.3 \pm 0$ & $1.3 \pm 0$ & $1.4 \pm 0.2$ & $42.3 \pm 0.4$ & $5.0 \pm 0.2$ & $0.2 \pm 0$ & $11.6 \pm 0.1$ \\
\hline
\end{tabular}

retardant according to our previous study. It has been shown that the thermal insulation materials containing $20 \%$ expandable graphite or $25 \%$ synergetic fire retardant can meet the requirements of fire class $\mathrm{E}$ according to the European standard (CEN [3]; ISO [2]), and show an enhanced fire retardancy (Zheng et al. [1]). The mixtures were mechanically stirred (3000 rpm, $15 \mathrm{~min}$ ) in an L\&W Pulp Disintegrator (ABB, Zürich, Switzerland) to form foams, and then the foams that were drained by gravity for $30 \mathrm{~min}$, followed by drying $\left(90{ }^{\circ} \mathrm{C}, 8 \mathrm{~h}\right)$ in a TS8000 oven (TERMAKS, Bergen, Norway). The insulating materials containing the expandable graphite or synergetic fire retardants were denoted EGIM or SYIM (Fig. 1). A reference material was prepared from a suspension of CTMP without any addition of fire retardant.

\section{Thermal analysis}

The thermal degradation behavior of the samples was determined by TG, using a TGA/SDTA 851e (Mettler Toledo, Greifensee, Zürich, Switzerland). The samples (about $2 \mathrm{mg}$ ) were heated from 25 to $800{ }^{\circ} \mathrm{C}$ at heating rates of $5,10,15$, or $20^{\circ} \mathrm{C} \min ^{-1}$ in an inert atmosphere (a $50-\mathrm{mL} \mathrm{min}^{-1}$ flow of nitrogen). The onset temperature (temperature in $10 \%$ dry mass loss), the maximum decomposition temperature at the maximum mass loss, the production of volatiles in various temperature zones $\left(25-150,200-375\right.$, and $\left.375-800{ }^{\circ} \mathrm{C}\right)$, and the residue at $800{ }^{\circ} \mathrm{C}$ were measured.

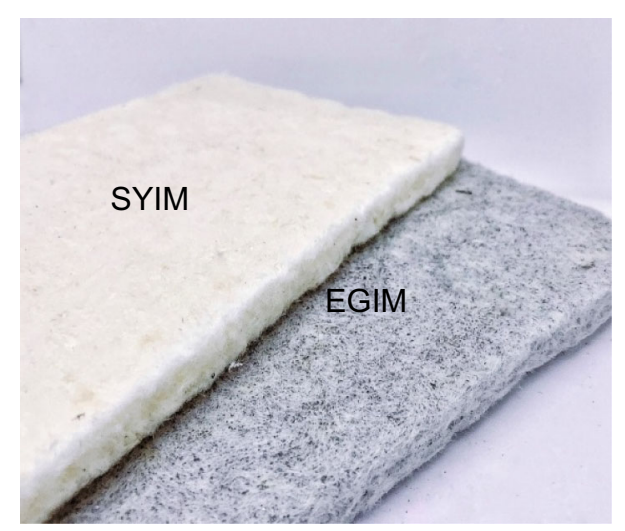

Fig. 1 Photographs of the samples containing expandable graphite or synergetic intumescent fire retardant

\section{Thermal degradation kinetics}

The thermal degradation kinetics parameters $\left(E_{\mathrm{a}}, f(a), \mathrm{A}\right)$ can be accessed by two main approaches: isothermally where the temperature keeps constant over time, or nonisothermally where the temperature varies with temperature and time and is dependent on the heating rate $(\beta)$. Compared with the method based on a single heating rate, the methods based on multiple-heating rates (model-free or isoconventional methods) make it easier to determine the $E_{\mathrm{a}}[21]$.

Therefore, model-free (isoconventional) methods: the KAS [5-7], the Friedman [8], and the FWO methods $[9,10]$ were used to determine the $E_{\mathrm{a}}$ and confirm the reliability of the values of $E_{\mathrm{a}}$, and master-plots method such as the Criado method [19] was used to identify the possible degradation mechanism.

The thermal decomposition of a solid polymer can usually be described as $A_{\text {solid }} \rightarrow B_{\text {solid }}+C_{\text {gas }}$. The degree of conversion $a$ can be calculated using the equation:

$\alpha=\frac{W_{0}-W_{\mathrm{t}}}{W_{0}-W_{\infty}}$

where $W_{0}, W_{t}$, and $W_{\propto}$ are the initial, actual, and final mass of the sample in the TG, respectively. The initial mass of the sample $W_{0}$ is the mass of the sample at $373.15 \mathrm{~K}$ to minimize the effect of moisture content on the results of activation energy.

A fundamental reaction rate of the kinetic degradation process can be expressed by the Arrhenius equation:

$\frac{\mathrm{d} \alpha}{\mathrm{d} t}=k f(\alpha)$

The rate constant associated with the temperature $k$ is usually defined by the equation:

$k=A \mathrm{e}^{-\frac{\mathrm{E}_{\alpha}}{\mathrm{RT}}}$

By combining Eqs. (2) and (3), the reaction rate can be written as:

$\frac{\mathrm{d} \alpha}{\mathrm{d} t}=A \mathrm{e}^{-\frac{\mathrm{E} \alpha}{\mathrm{RT}}} f(\alpha)$

The constant heating rate in TG is defined as $\beta=\mathrm{d} T / \mathrm{d} t$, and the reaction rate can be expressed as:

$\frac{\mathrm{d} \alpha}{\mathrm{d} t}=\frac{\mathrm{d} T}{\mathrm{~d} t} \frac{\mathrm{d} \alpha}{\mathrm{d} T}=\beta \frac{\mathrm{d} \alpha}{\mathrm{d} T}$ 
By combining Eqs. (4) and (5), the reaction rate can be described as:

$\frac{\mathrm{d} \alpha}{\mathrm{d} T}=\frac{A}{\beta} \mathrm{e}^{-\frac{\mathrm{E}_{\alpha}}{\mathrm{RT}}} f(\alpha)$

Integration of Eq. (6) with the initial conversion degree $a=0$ at $T=T_{0}$ leads to:

$g(\alpha)=\int_{0}^{\alpha} \frac{\mathrm{d} \alpha}{f(\alpha)}=\frac{A}{\beta} \int_{T_{0}}^{T} \mathrm{e}^{-\frac{E_{\alpha}}{R T}} \mathrm{~d} T \equiv \frac{A E_{\alpha}}{\beta R} \mathrm{p}\left(\frac{E_{\alpha}}{R T}\right)$

$g(a)$ has different expressions (Table S1) that can be used to predict the solid reaction mechanism in the dynamic TG.

\section{Model-free methods}

The KAS method [5-7] Equation (7) can be integrated into a logarithmic form as the equation:

$\ln g(\alpha)=\ln \left(\frac{A E_{\alpha}}{R}\right)-\ln \beta+\ln \left[p\left(\frac{E_{\alpha}}{R T}\right)\right]$

Introducing the approximation

$p\left(\frac{E_{\alpha}}{R T}\right) \cong \frac{\mathrm{e}^{-\frac{\mathrm{E} \alpha}{\mathrm{RT}}}}{\left(\frac{E_{\alpha}}{R T}\right)^{2}}$

Equation (8) can be rewritten as the KAS equation:

$\ln \frac{\beta}{T^{2}}=\ln \frac{A R}{E_{\alpha} g(\alpha)}-\frac{E_{\alpha}}{R T}$

Activation energies $E_{\mathrm{a}}$ can be calculated from the slope of $\ln \left(\beta / T^{2}\right)$ versus $1000 / T$ for different heating rates $\beta$. The slope is equal to $-E_{\alpha} / \mathrm{R}$.

The Friedman method [8] Based on the logarithms of Eqs. (5) and (6), the Friedman method can be described by the equation:

$\ln \frac{\mathrm{d} \alpha}{\mathrm{d} t}=\ln \left(\beta \frac{\mathrm{d} \alpha}{\mathrm{d} T}\right)=\ln [A f(\alpha)]-\frac{E_{\alpha}}{R T}$

Activation energies $E_{\mathrm{a}}$ can be obtained from the slope of the plots of $\ln (\mathrm{d} \alpha / \mathrm{d} t)$ versus $1000 / T$, and the slope is equal to $-E_{\alpha} / \mathrm{R}$.

The FWO method [9, 10] Using Doylés approximation $\ln p\left(\frac{E_{\alpha}}{R T}\right) \cong-5.3305-1.052 \frac{E_{\alpha}}{R T}[22,23]$, Eq. (8) can be simplified to:

$\ln \beta=\ln \frac{A E_{\alpha}}{R g(\alpha)}-5.3305-1.052 \frac{E_{\alpha}}{R T}$

\section{Master-plots method}

The Criado method [19] By combining Eqs. (5) and (6), the Criado method can be described by the expression:

$\frac{Z(\alpha)}{Z(0.5)}=\frac{f(\alpha) g(\alpha)}{f(0.5) g(0.5)}=\left(\frac{T_{\alpha}}{T_{0.5}}\right)^{2} \frac{(\mathrm{d} \alpha / \mathrm{d} t)_{\alpha}}{(\mathrm{d} \alpha / \mathrm{d} t)_{0.5}}$

where 0.5 indicates the degree of conversion $a$.

$\frac{f(\alpha) g(\alpha)}{f(0.5) g(0.5)}$ is used to plot the theoretical model curves by introducing the different $f(a)$ and $g(a)$ expressions, while the $\left(\frac{T_{\alpha}}{T_{0.5}}\right)^{2} \frac{(\mathrm{d} \alpha / \mathrm{d} t)_{\alpha}}{(\mathrm{d} \alpha / \mathrm{d} t)_{0.5}}$ is obtained from the experimental data.

Table 2 summarizes the different thermal degradation kinetic methods. The different algebraic expressions for $f(a)$ and $g(a)$ for the kinetic models are listed in Table S1 [24].

\section{Py-GC-MS}

The volatile gases released during the thermal degradation of the materials were determined by Py-GC/MS consisting of a TGA/DSC $3^{+}$(Mettler Toledo, Greifensee, Zürich, Switzerland), a sample storage unit IST16 (SRA Instrument Chromatographic Solutions, Marcy-l'Étoile, Lyon, France), 7820A GC, and a 5977B MSD System (Agilent Technologies, Santa Clara, California, United States). The samples were heated from 25 to $800{ }^{\circ} \mathrm{C}$ at a rate of $10{ }^{\circ} \mathrm{C} \mathrm{min}{ }^{-1}$ in an inert atmosphere $\left(30 \mathrm{~mL} \mathrm{~min}^{-1}\right.$ flow of nitrogen). The volatile gases at 250, 350, and $450{ }^{\circ} \mathrm{C}$ were identified according to their mass spectra using a NIST MS library.

\section{Results and discussion}

\section{Thermal degradation analysis}

Figure 2 shows the TG curves and derivative (DTG) curves of the SYIM and EGIM fire-retardant cellulosic thermal insulating materials at a heating rate of $10{ }^{\circ} \mathrm{C} \mathrm{min}-1$, and the results are summarized in Table $\mathrm{S} 2$. The onset decomposition temperatures (temperature for $10 \%$ mass loss $-T_{\text {onset } 10 \%}$ ) for EGIM and SYIM were lower than that of the reference. A decrease in thermal stability could promote an earlier dehydration of the materials and generate a protective char layer on the surface of the materials at a lower temperature [25]. An increase in the final char residue (about 12\%) of the fire-retardant insulating materials was also observed in the TG curves.

As shown in the DTG curves (Fig. 2b), Tmax for the reference sample likely related to the dehydration of 
Table 2 Methods used in the evaluation of kinetic parameters and mechanisms

\begin{tabular}{lll}
\hline Method & Expression & Plot \\
\hline Model-free method & $\ln \frac{\beta}{T^{2}}=\ln \frac{A R}{E_{\alpha} g(\alpha)}-\frac{E_{\alpha}}{R T}$ & $\ln \frac{\beta}{T^{2}}$ versus $\frac{1}{T}$ \\
KAS & $\ln \frac{\mathrm{d} \alpha}{\mathrm{d} t}=\ln [A f(\alpha)]-\frac{E_{\alpha}}{R T}$ & $\ln \frac{\mathrm{d} \alpha}{\mathrm{d} t} \operatorname{versus} \frac{1}{T}$ \\
Friedman & $\ln \beta=\ln \frac{A E_{\alpha}}{R g(\alpha)}-5.3305-1.052 \frac{E_{\alpha}}{R T}$ & $\ln \beta$ versus $\frac{1}{T}$ \\
FWO & & \\
Master-plots method & \\
Criado & $\frac{Z(\alpha)}{Z(0.5)}$ versus $\alpha$ \\
\hline
\end{tabular}

(a)

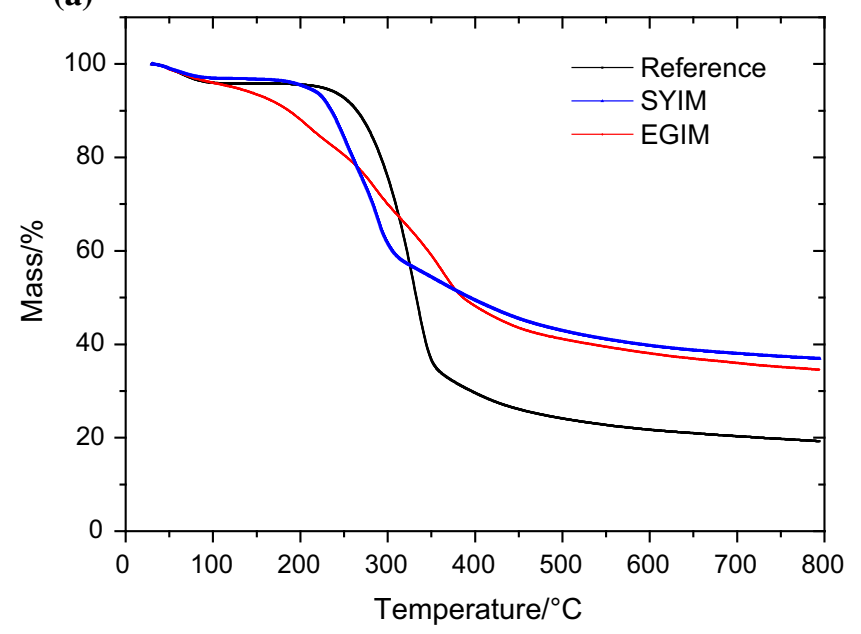

(b)

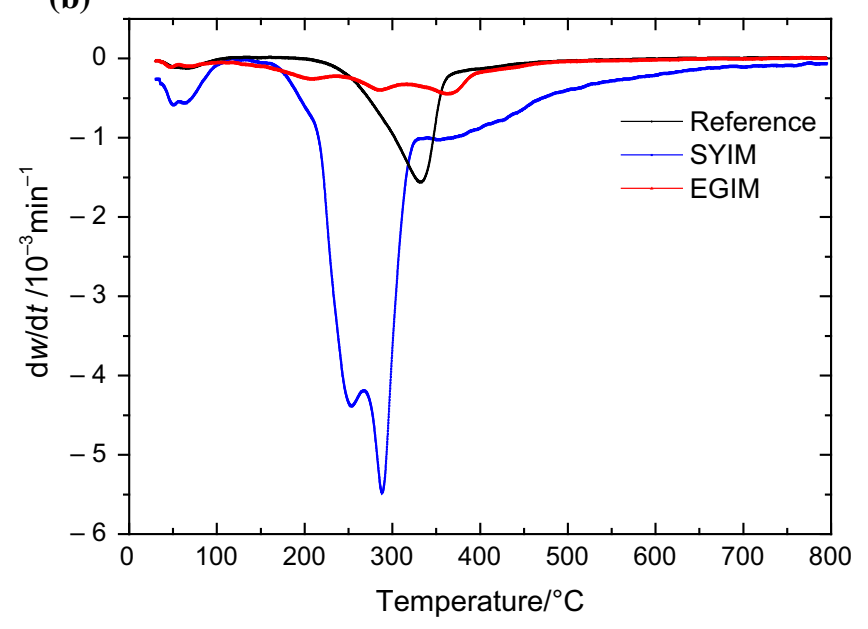

Fig. 2 a TG and b DTG curves for the reference and fire retardant-containing insulating materials

cellulose and hemicellulose which were predominant at temperatures lower than $300{ }^{\circ} \mathrm{C}$, while lignin decomposition was less significant due to its lower content of free hydroxyls in this temperature region [26]. Tmax ${ }_{1}$ for EGIM was much lower than that for SYIM $\left(209\right.$ vs. $\left.254^{\circ} \mathrm{C}\right)$. On the other hand, $\operatorname{Tmax}_{3}$ for EGIM was obviously higher than $\mathrm{Tmax}_{2}$ for SYIM (362 vs. $288^{\circ} \mathrm{C}$ ). The higher Tmax was here attributed to the generation of a more thermally stable char, as a result of the degradation of expandable graphite [27] and the dehydration of pulp fibers. $T_{\text {onset } 10 \%}$ for EGIM was $197{ }^{\circ} \mathrm{C}$, which was related to the expansion of the expandable graphite pulp fibers into a "worm"-like char layer at a low temperature $160{ }^{\circ} \mathrm{C}$ due to the redox reaction between the inserted $\mathrm{H}_{2} \mathrm{SO}_{4}$ and the layered graphite [14]. For the SYIM sample, the $\operatorname{Tmax}_{1}\left(254{ }^{\circ} \mathrm{C}\right)$ could be due to the decomposition of aluminum hydroxide (ATH) at a temperature of $180{ }^{\circ} \mathrm{C}$ [15]; and the catalytic dehydration of pulp fibers by the polyphosphates produced in the decomposition of ammonium polyphosphate (APP) [16]. As a result, the thermally stable char generated and that resulted in a higher $\operatorname{Tmax}_{2}$ for SYIM. However, the rate of decomposition of the SYIM was faster than that of the EGIM according to the DTG curves, which could be due to synergetic effects of APP and ATH in SYIM. The water-soluble ammonium sulfate was not considered in the discussion, since it may have been lost during the wet production process as indicated by the retention calculation in the previous work [4].

The dynamic TG and DTG curves at different heating rates (Fig. 3) show that the decomposition temperature increased when the heating rate rose from 5 to $20{ }^{\circ} \mathrm{C} \mathrm{min}-1$. There was a slight shift to a higher onset temperature and to a higher maximum temperature with increasing heating rate (Table S2) even though the TG and DTG profiles were similar, which could result from the higher thermal gradient in the sample crucible with increasing heating rate [28], i.e., the heat transfer was not uniform between the furnace and samples when the heating rate was faster [29], and there was a thermal lag between the thermosensor and the sample $[12,30]$.

These TG curves (Fig. 3a, c, and e) show different mass loss stages. Stage I, between 25 and $150{ }^{\circ} \mathrm{C}$, Stage II, between 200 and $375{ }^{\circ} \mathrm{C}$, and Stage III, between 375 and $800{ }^{\circ} \mathrm{C}$. The quantities of volatiles released during these thermal degradation stages are presented in Table S2. The quantity of volatiles produced from a given material is 

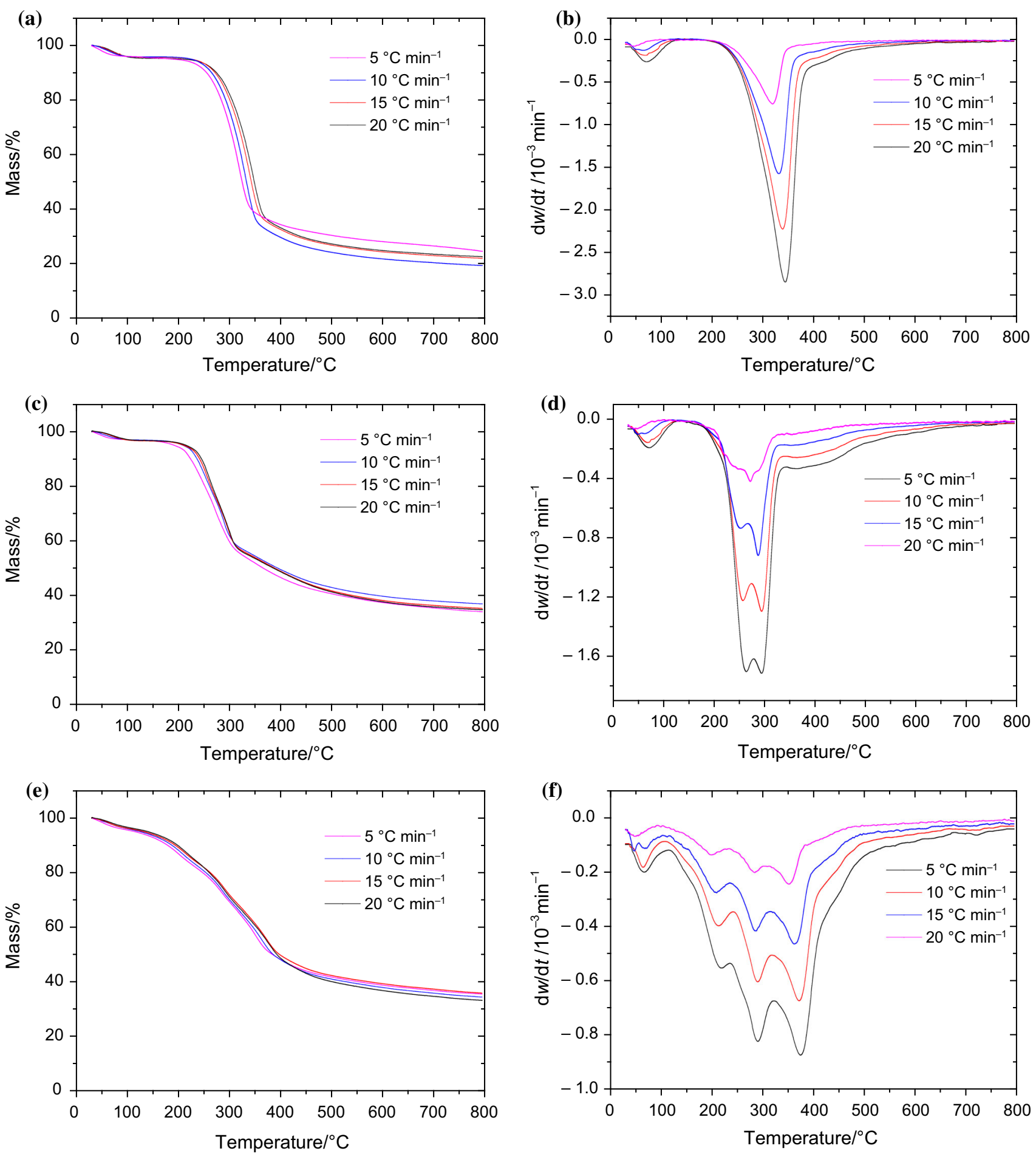

Fig. 3 TG and DTG curves of the samples at different heating rates: a TG-reference; b DTG-reference; c TG-SYIM; d DTG-SYIM; e TGEGIM; f DTG-EGIM

more or less the same regardless of the increasing heating rate, e.g., the total volatile of the reference sample kept at about $77 \%$ when the heating rate increased from 5 to $20{ }^{\circ} \mathrm{C} \min ^{-1}$. In stage I, 3-7\% moisture mainly volatilized between 25 and $150{ }^{\circ} \mathrm{C}$. In stage II, a complicated thermal degradation process with several overlapping peaks in the DTG curves was observed between 200 and $375^{\circ} \mathrm{C}$, and the volatilization was 60,45 , and $35 \%$, respectively, for the reference, SYIM, and EGIM. The lower volatile production implies that the 

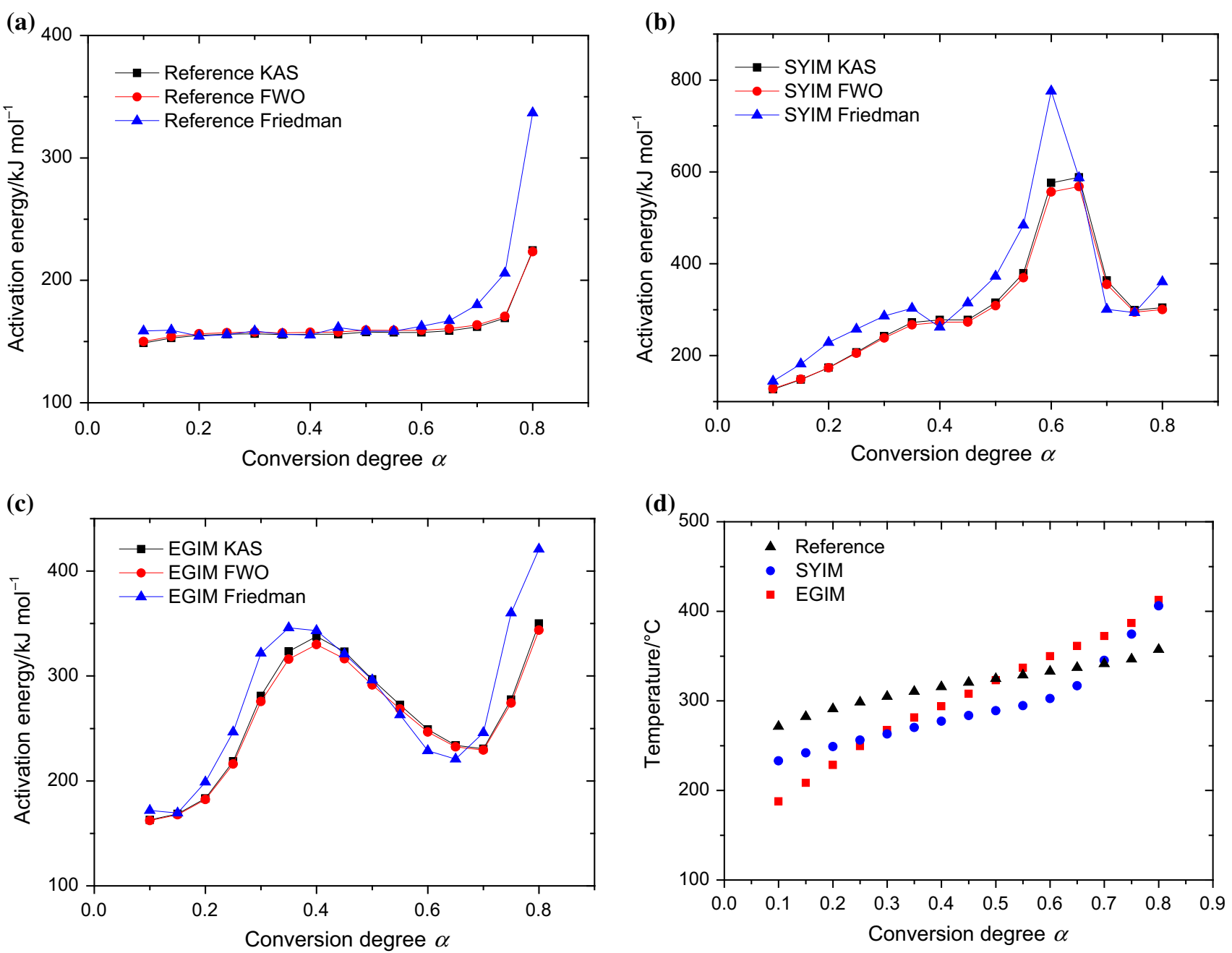

Fig. 4 Activation energy as a function of conversion calculated by different methods: a reference; b SYIM; $\mathbf{c}$ EGIM; $\mathbf{d}$ temperature as a function of the degree of conversion at a heating rate of $10^{\circ} \mathrm{C} \min ^{-1}$

dehydration of the pulp fiber is promoted and that the char formation is increased. In stage III, fire-retardant samples SYIM and EGIM showed a higher volatilization than the reference in the range of $375-800{ }^{\circ} \mathrm{C}$, as could be concluded by further reactions of char formation.

\section{Calculation of the activation energy according to the model-free methods}

The activation energy $E_{\alpha}$ values were calculated according to the KAS, Friedman, and FWO methods (Fig. 4a, b, and c; Table S3), and the linear plots $\ln \left(\beta / T^{2}\right)$ versus $1 / T, \ln (\mathrm{d} \alpha /$ $\mathrm{d} t$ ) versus $1 / T$, and $\ln \beta$ versus $1 / T$ are shown in Fig. S1. For the reference sample without fire retardant, it has been seen that the plots (Fig. S1 a, b, and c) showed a good linear when the degree of conversion in the range of $0.15-0.6$ at corresponding temperature of $280-330{ }^{\circ} \mathrm{C}$ (Fig. $4 \mathrm{~d}$ ), which could imply constant activation energies at different conversions and the possibility of single reaction mechanism (or the unification of multiple-step reaction mechanisms). For the fire-retardant insulating samples SYIM and EGIM (Fig. S1 d-i), the linear relationship was not significant when $\alpha<0.3$ and $\alpha>0.6$, which might be due to the complex reactions in the decomposition process of the fire retardant and the dehydration of cellulosic fibers.

The activation energy for each degree of conversion shown in Table S3 was calculated from the slope of the fitted linear line obtained by different kinetic methods. Figure 4 shows the plots of activation energy as a function of conversion in the range of $0.1-0.8$ for all the samples. For the reference sample, the data obtained by the KAS, Friedman and FWO methods were very close and in good agreement when $\alpha<0.6$, which indicated the reliability of the $E_{\alpha}$ values obtained. An increased $E_{\alpha}$ indicates a greater thermal stability due to the formation of a thermally stable char when $\alpha>0.6$. But for the fire-retardant insulating samples SYIM and EGIM, the thermal decomposition may be a multiple-step mechanism because the 

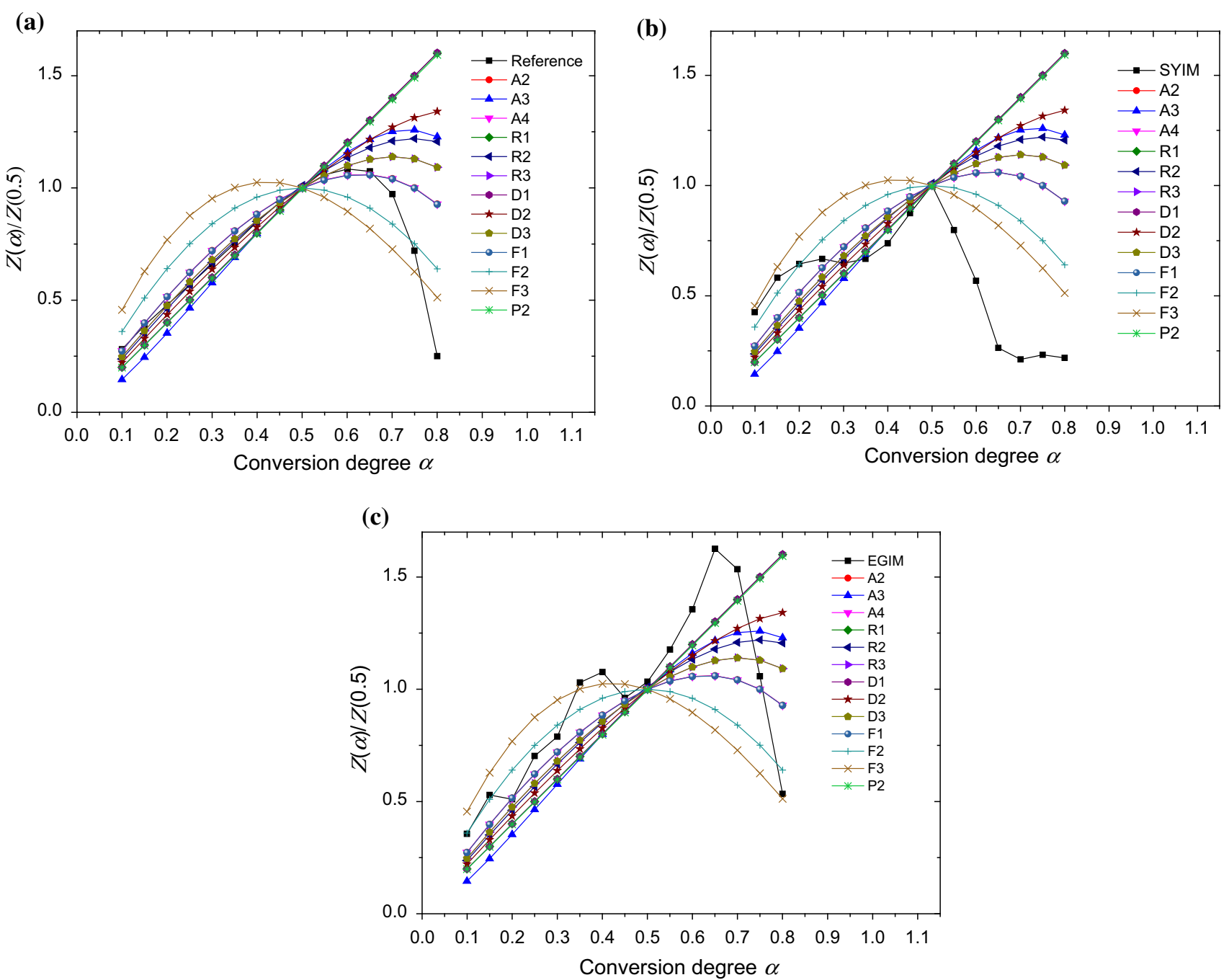

Fig. 5 Master curves and experimental curves at $10{ }^{\circ} \mathrm{C} \min ^{-1}$ obtained using the Criado method: a reference; b SYIM; c EGIM

relationship between $E_{\alpha}$ and $\alpha$ was not linear. The Friedman method produced higher $E_{\alpha}$ values than the KAS and FWO methods (Table S3). The numerical difference between the methods for SYIM and EGIM was 10-25\%. According to the previous study, the Friedman method is usually the most accurate compared with the KAS and FWO methods when the actual $E_{\alpha}$ value varies with the degree of conversion $\alpha$ [31]. Because the KAS and FWO methods assume that the value of $E_{\alpha}$ is constant in the whole interval of integration $(0-\alpha)$. A $20-30 \%$ of systematic error could be introduced when the $E_{\alpha}$ value has significant variations. However, the differential method of Friedman can eliminate this error. Thus, the Friedman method can be regarded as the best method to evaluate the kinetic parameters compared with other model-free methods such as KAS and FWO [31-34]. For SYIM and EGIM, the activation energy varied significantly at the higher degree of conversions, indicating the existence of a complex multi- step mechanism including parallel, competitive, and consecutive reactions and activation energies [35].

The $E_{\alpha}$ can be divided into several regions with regards to $\alpha$. For the reference, $E_{\alpha}$ remained constant at about $160 \mathrm{~kJ} \mathrm{~mol}^{-1}$ in the main region $(0.15 \leq \alpha \leq 0.6)$. For SYIM, $E_{\alpha}$ remained constant in the region $0.35 \leq \alpha$ $\leq 0.45$, and increased significantly in the region $(0.5 \leq$ $\alpha \leq 0.6)$, before decreasing gradually $(0.65 \leq \alpha \leq 0.8)$. For EGIM, an increase in $E_{\alpha}$ was evident in the region $(0.1 \leq \alpha \leq 0.4)$ and $a$ decrease in the region $(0.4 \leq \alpha \leq 0.7)$.

As shown in Fig. $4 \mathrm{a}, \mathrm{b}$, and c, the $E_{\alpha}$ value of SYIM increased gradually when the degree of conversion was increased from 0.1 to 0.65 , and the $E_{\alpha}$ value of EGIM showed an increasing trend when the $\alpha$ was below 0.4 , in contrast that of the reference that remained constant at about $160 \mathrm{~kJ} \mathrm{~mol}^{-1}$. This indicated that the fire retardants improved the formation of a thermally stable char. In 
(a)

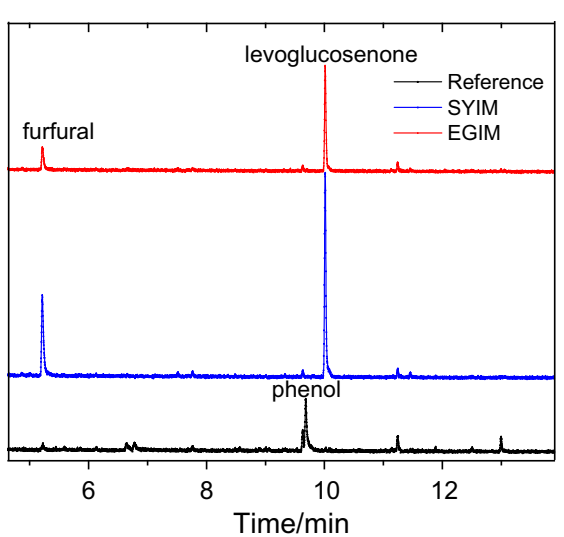

(b)

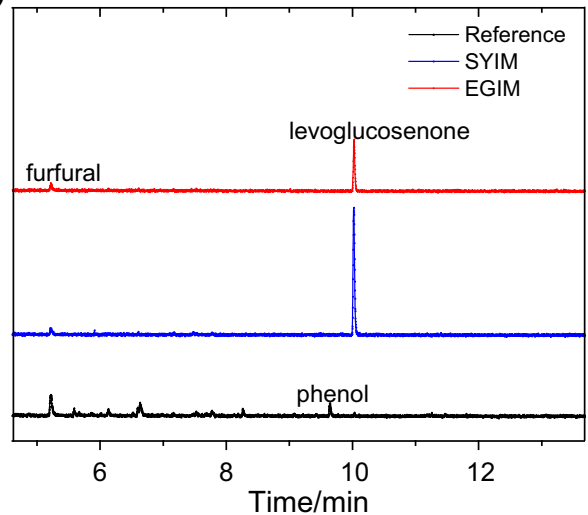

(c)

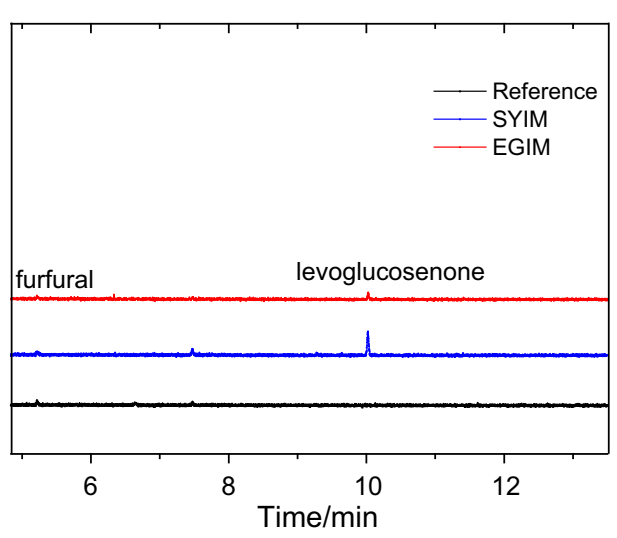

Fig. 6 Gas chromatogram of the volatile products formed during thermal degradation (in $\mathrm{N}_{2}$ ) of cellulosic thermal insulating materials at a $250{ }^{\circ} \mathrm{C} ; \mathbf{b} 350{ }^{\circ} \mathrm{C} ; \mathbf{c} 450{ }^{\circ} \mathrm{C}$

general, the activation energy is defined as the minimum energy needed to start a chemical reaction, and a higher $E_{\alpha}$ value means a slower reaction [12]. Here, a higher $E_{\alpha}$ indicates a greater thermal stability because of the generation of a thermally stable char. The trend is similar to that of fire-retardant materials previously reported [12, 17, 36]. A lower $E_{\alpha}$ after the increasing region can be related to the catalytic reaction of phosphoric acid produced from the decomposition of APP or of $\mathrm{H}_{2} \mathrm{SO}_{4}$ between the carbon layers in EG. The reaction catalyzed the dehydration of the main components (cellulose, hemicellulose, and lignin) of the pulp fibers and led to a lower $E_{\alpha}$.

Figure $4 d$ shows the temperature as a function of the degree of conversion for the reference, SYIM, and EGIM at a heating rate of $10{ }^{\circ} \mathrm{C} \mathrm{min}^{-1}$. In the early thermal degradation stage ( $\alpha=0.1$ ), the $E_{\alpha}$ value of the fire-retardant cellulosic thermal insulating materials SYIM was lower than that of the reference without any fire retardant, and the temperatures at $\alpha=0.1$ showed the same tendency. This means the decomposition of synergetic fire retardant and the dehydration of pulp fibers at a lower temperature, which is similar to the results for the fire-retardant wood plastic composite [36]. In contrast, the $E_{\alpha}$ of EGIM $(\alpha=$
0.1) was higher than that of the reference and SYIM, indicating a slower decomposition of pulp fibers due to the earlier generation of protective char during the redox reaction between $\mathrm{H}_{2} \mathrm{SO}_{4}$ and the graphite.

\section{Determination of the degradation mechanism by the master-plots method}

The $Z(\alpha) / Z(0.5)$ versus $\alpha$ curves based on the different mechanisms $f(\alpha)$ are shown in Fig. 5. For the reference, the experimental curve almost overlapped the D3 curve in the range $(0.1<\alpha<0.6)$ (Fig. 5a), indicating that the reference without any fire retardant could possibly be governed by a D3 mechanism, where degradation occurs by diffusion in three dimensions (diffusion of heat from heating source and hot gases produced throughout the sample). This is in accordance with the results previously reported [37-40]. When the conversion values are higher than 0.6 , the suitable mechanism model was difficult to identify, which could be due to the complex degradation of char.

For SYIM and EGIM, in the beginning, the experimental curves $(0.1 \leq \alpha \leq 0.15)$ could overlap F3 and F2 theoretical models, respectively. But with the increasing of 
Table 3 Volatile pyrolysis products of cellulosic thermal insulating materials heated at $250{ }^{\circ} \mathrm{C}$

\begin{tabular}{|c|c|c|c|c|c|c|}
\hline \multirow[t]{2}{*}{ Compounds } & \multirow[t]{2}{*}{ Formula } & \multirow{2}{*}{$\begin{array}{l}\text { Retention time/ } \\
\text { min }\end{array}$} & \multirow{2}{*}{$\begin{array}{l}\text { Molecular mass/ } \\
\mathrm{g} \mathrm{mol}^{-1}\end{array}$} & \multicolumn{3}{|c|}{ Area percentage $/ \%$} \\
\hline & & & & Reference & SYIM & EGIM \\
\hline Furfural & $\mathrm{C}_{5} \mathrm{H}_{4} \mathrm{O}_{2}$ & 5.22 & 96 & 5.5 & 28.3 & 20.9 \\
\hline 2(5H) Furanone & $\mathrm{C}_{4} \mathrm{H}_{4} \mathrm{O}_{2}$ & 6.65 & 84 & 6.9 & - & - \\
\hline 2-Cyclopenten-1-one, 2-hydroxy- & $\mathrm{C}_{5} \mathrm{H}_{6} \mathrm{O}_{2}$ & 6.78 & 98 & 7.5 & - & - \\
\hline Phosphoric acid, dimethyl 1-propenyl ester & $\mathrm{C}_{5} \mathrm{H}_{11} \mathrm{O}_{4} \mathrm{P}$ & 7.52 & 166 & - & 3.0 & - \\
\hline Carbonic acid, butyl phenyl ester & $\mathrm{C}_{11} \mathrm{H}_{14} \mathrm{O}_{3}$ & 7.77 & 194 & 2.9 & 1.7 & - \\
\hline Phenol, 2-methoxy- & $\mathrm{C}_{7} \mathrm{H}_{8} \mathrm{O}_{2}$ & 9.63 & 124 & 11.4 & 2.3 & 4.1 \\
\hline Cyclopropyl carbinol & $\mathrm{C}_{4} \mathrm{H}_{8} \mathrm{O}$ & 9.68 & 72 & 40.4 & - & - \\
\hline Levoglucosenone & $\mathrm{C}_{6} \mathrm{H}_{6} \mathrm{O}_{3}$ & 10.03 & 126 & 1.7 & 61.4 & 67.6 \\
\hline 3-Acetyl-2,5-dimethyl furan & $\mathrm{C}_{8} \mathrm{H}_{10} \mathrm{O}_{2}$ & 11.14 & 138 & 1.9 & - & - \\
\hline Phenol, 4-methoxy-3-methyl- & $\mathrm{C}_{8} \mathrm{H}_{10} \mathrm{O}_{2}$ & 11.24 & 138 & 8.0 & 2.1 & 6.0 \\
\hline $\begin{array}{l}\text { Phosphonic acid, phenyl-, bis[5-methyl-2-(1- } \\
\text { methylethyl)cyclohexyl] ester }\end{array}$ & $\mathrm{C}_{26} \mathrm{H}_{43} \mathrm{O}_{3} \mathrm{P}$ & 11.46 & 434 & - & 1.2 & - \\
\hline Benzene, 1,4-dimethoxy-2-methyl- & $\mathrm{C}_{9} \mathrm{H}_{12} \mathrm{O}_{2}$ & 11.89 & 152 & 1.7 & - & - \\
\hline Phenol, 4-ethyl-2-methoxy- & $\mathrm{C}_{9} \mathrm{H}_{12} \mathrm{O}_{2}$ & 12.51 & 152 & 3.5 & - & - \\
\hline 2-Methoxy-4-vinylphenol & $\mathrm{C}_{9} \mathrm{H}_{10} \mathrm{O}_{2}$ & 12.99 & 150 & 8.2 & - & - \\
\hline
\end{tabular}

$\alpha$, these fire-retardant samples showed very complicated reaction mechanisms or may have deviated from the basic theoretical models, e.g., the experimental curve of SYIM may fit the A3 model when the $\alpha$ value was between 0.35 and 0.5. It did not fit the proposed models when the $\alpha$ increased from 0.5 to 0.8 . For EGIM, the experimental curve could overlap the F2, F3, and P2 models alternately when the $\alpha$ was lower than 0.5 , i.e., it probably fit F2 $(0.1 \leq \alpha \leq 0.15,0.25 \leq \alpha \leq 0.3)$, F3 $(0.35 \leq \alpha \leq 0.4)$, and P2 $(0.45 \leq \alpha \leq 0.5)$. Similarly, no proposed models overlapped the experimental curve when the $\alpha$ was higher than 0.5 .

\section{Analysis of volatile products of thermal degradation using Py-GC-MS}

Gas chromatograms of the volatile products during the thermal degradation of insulating materials are shown in Fig. 6, i.e., the volatile products produced from the thermal degradation of the major components of CTMP fibers (such as cellulose, hemicellulose, and lignin). As summarized in Table 1, the CTMP raw material consisted mainly of $42 \%$ of glucose, $26 \%$ of lignin, and $20 \%$ of monosaccharidecontaining hemicellulose. Cellulose is a long-chain polymer with alternating repeating units of glucose linked by $\beta$ 1,4-glycosidic bonds [41]. Hemicellulose consists of a variety of monomers such as xylose, mannose, glucose, galactose, and arabinose. Hemicellulose has a more complex structure than cellulose due to its higher content of branched chains attached to the backbone through glycosidic linkages [42]. Lignin is composed of three basic monomeric units, syringyl, guaiacyl, and p-hydroxyphenyl alcohol [43].

As shown in Fig. 6a, fire-retardant materials released a large quantity of furfural that could be derived from the loss of formaldehyde of the cyclic or chain conformations of $\beta$-D-glucose in cellulose [44]. Similarly, the improved formation of levoglucosenone could result from the accelerated degradation of $\beta$-D-glucose. The dehydration of cellulose and hemicellulose generated $\mathrm{C}=\mathrm{C}$ bonds through cleavage of the glycosidic links [45]. In addition, the generation of phenols was suppressed when the fire retardants were present so that less volatile phenol compounds were formed from lignin and more solid char generation arose from the catalysis of the fire retardants [46]. Also, rearrangement of the aromatic rings occurred, resulting in a reduction in the amount of volatile aromatic compounds [47].

The SYIM produced more furfural and levoglucosenone than EGIM, which may be attributed to the formation of polyphosphates during the degradation of APP. This reaction can enhance the catalysis of the char generation and promote the formation of anhydrosugars. Acidic metal oxides such as aluminum oxide produced from ATH also increased the total yield of anhydrosugars (levoglucosenone) as a result of the promotion of the dehydration, decarbonylation and cracking of organic molecules [48]. Besides, the significant increase in furfural yield may be attributed to the improved catalytic dehydration of the pentosyl and glucosyl residues and anhydrosugars [49]. 
Furfural was the most abundant product created during the degradation of hemicellulose when monosaccharide units in hemicellulose were ring-opened and cracked [50].

The release of furfural and levoglucosenone increased, which is linked to the onset temperature shift in TG (Fig. 2a) and the destabilization in the DTG curve (Fig. 2b). Intensive dehydration of glycoside units of cellulose leads to an increase in the production of levoglucosenone from a potential catalyzed degradation [51]. This result agrees with what has been reported by Czégény et al. [52] and by Pappa et al. [53]. A possible reaction pathway [45] for the formation of levoglucosenone from cellulose is shown in Fig. S2. As shown in Fig. 6, the yield of furfural and levoglucosenone dramatically decreased with increasing temperature from 250 to $450{ }^{\circ} \mathrm{C}$, because of the char formation.

Most of the identified pyrolysis products and the percentages of the individual products are presented in Table 3. In the volatiles from SY, the phosphoric acid, dimethyl 1-propenyl ester $\left(\mathrm{C}_{5} \mathrm{H}_{11} \mathrm{O}_{4} \mathrm{P}\right)$ and phosphonic acid, phenyl-, bis[5-methyl-2-(1-methyl ethyl)cyclohexyl] ester $\left(\mathrm{C}_{26} \mathrm{H}_{43} \mathrm{O}_{3} \mathrm{P}\right)$ were found, which further supports the discussion about the fire retardancy mechanism of SYIM.

\section{Conclusions}

Fire-retarded cellulose thermal insulation was produced from mechanical pulp and synergetic fire retardant or expandable graphite by a foam-forming technique, and the final materials can fulfill the requirements of fire safety in energy-efficient buildings. To understand the fire retardancy mechanism and predict the thermal behavior of fireretardant thermal insulating materials, the thermal degradation kinetics of cellulose fiber-based thermal insulating materials have been systematically investigated. Fire-retardant thermal insulating materials consisting of cellulose fiber and synergetic fire retardant or expandable graphite had a gradual increase in the apparent activation energies in the early decomposition process. The reaction mechanism of the reference material followed a diffusion model (D3) when the conversion values were below 0.6, but the fire-retardant samples containing synergetic fire retardant or expandable graphite exhibited complex reaction mechanisms that involved in several proposed theoretical models in different conversion ranges. The Friedman method can be expected as the most accurate method to determinate the kinetic parameters compared with KissingerAkahira-Sunose and Flynn-Wall-Ozawa methods.

Analysis of thermal degradation gases showed that the fire retardants could catalyze the degradation of cellulosic fibers as well as increase the total yields of anhydrosugars (levoglucosenone) and furfural resulting from the dehydration of carbohydrates. A decrease in the yield of volatile phenols and an increased formation of solid char were in agreement with the proposed mechanism of fire retardancy.

Acknowledgements C. Zheng acknowledges the China Scholarship Council for offering financial support to this doctoral program. The Swedish Research Council Formas (Grant/Award number: "20146986-29014-28") is acknowledged for the financial support provided to the project: "Energy-efficient cellulosic insulation products/panels for green building solutions." Rottneros AB (Söderhamn, Sweden) is thanked for providing the raw materials.

Open Access This article is distributed under the terms of the Creative Commons Attribution 4.0 International License (http://creative commons.org/licenses/by/4.0/), which permits unrestricted use, distribution, and reproduction in any medium, provided you give appropriate credit to the original author(s) and the source, provide a link to the Creative Commons license, and indicate if changes were made.

\section{References}

1. Zheng C, Li D, Ottenhall A, Ek M. Cellulose fiber based fungal and water resistant insulation materials. Holzforschung. 2017;71(7-8):633-9. https://doi.org/10.1515/hf-2016-0162.

2. ISO. Reaction to fire tests. Ignitability of products subjected to direct impingement of flame. Single-flame source test. Standard 11925-2. Switzerland: International Organization for Standardization; 2010.

3. CEN. Fire classification of construction products and building elements. Classification using test data from reaction to fire tests. Standard 13501-1. Brussels, Belgium: European Committee for Standardization; 2007.

4. Zheng C, Li D, Ek M. Cellulose-fiber-based insulation materials with improved reaction-to-fire properties. Nord Pulp Pap Res J. 2017;32(3):466-72. https://doi.org/10.3183/NPPRJ-2017-32-03p466-472.

5. Kissinger HE. Reaction kinetics in differential thermal analysis. Anal Chem. 1957;29(11):1702-6. https://doi.org/10.1021/ ac60131a045.

6. Nasir M, Khan MAM, Husain M, Zulfequar M. Thermal properties of Se100-xZnx glassy system. Mater Sci Appl. 2011;2(05):289.

7. Akahira T, Sunose T. Joint convention of four electrical institutes. Res Rep Chiba Inst Technol. 1971;16:22-31.

8. Friedman HL. Kinetics of thermal degradation of char-forming plastics from thermogravimetry. Application to a phenolic plastic. J Polym Sci Polym Symp. 1964;6(1):183-95.

9. Flynn JH, Wall LA. A quick, direct method for the determination of activation energy from thermogravimetric data. J Polym Sci Part C Polym Lett. 1966;4(5):323-8.

10. Ozawa T. A new method of analyzing thermogravimetric data. B Chem Soc Jpn. 1965;38(11):1881-6.

11. Coats AW, Redfern J. Kinetic parameters from thermogravimetric data. Nature. 1964;201(4914):68-9.

12. Zhu F, Xu Y, Feng Q, Yang Q. Thermal kinetics study and flammability evaluation of polyimide fiber material. J Therm Anal Calorim. 2017;131(3):2579-87. https://doi.org/10.1007/ s10973-017-6752-z.

13. Girardin B, Fontaine G, Duquesne S, Försth M, Bourbigot S. Measurement of kinetics and thermodynamics of the thermal degradation for flame retarded materials: application to EVA/ 
ATH/NC. J Anal Appl Pyrol. 2017;124:130-48. https://doi.org/ 10.1016/j.jaap.2016.12.034.

14. Camino G, Duquesne S, Delobel R, Eling B, Lindsay C, Roels T. Mechanism of expandable graphite fire retardant action in polyurethanes. In: Nelson GL, Wilkie CA, editors. Fire and polymers., ACS symposium series, vol 797Washington, DC: American Chemical Society; 2001. p. 90-109.

15. Musbah Redwan A, Haji Badri K, Tarawneh MaA. The effect of aluminium hydroxide (ATH) on the mechanical properties and fire resistivity of palm-based fibreboard prepared by pre-polymerization method. Adv Mat Res. 2015;1087:287-92.

16. Seefeldt $\mathrm{H}$, Braun U, Wagner MH. Residue stabilization in the fire retardancy of wood-plastic composites: combination of ammonium polyphosphate, expandable graphite, and red phosphorus. Macromol Chem Phys. 2012;213(22):2370-7.

17. Chen Y, Wang Q. Thermal oxidative degradation kinetics of flame-retarded polypropylene with intumescent flame-retardant master batches in situ prepared in twin-screw extruder. Polym Degrad Stabil. 2007;92(2):280-91. https://doi.org/10.1016/j.poly mdegradstab.2006.11.004.

18. Chen Y, Liu Y, Wang Q, Yin H, Aelmans N, Kierkels R. Performance of intumescent flame retardant master batch synthesized through twin-screw reactively extruding technology: effect of component ratio. Polym Degrad Stabil. 2003;81(2):215-24. https://doi.org/10.1016/s0141-3910(03)00091-0.

19. Criado JM. Kinetic analysis of DTG data from master curves. Thermochim Acta. 1978;24(1):186-9.

20. Sánchez-Jiménez PE, Pérez-Maqueda LA, Perejón A, Criado JM. Generalized kinetic master plots for the thermal degradation of polymers following a random scission mechanism. J Phys Chem A. 2010;114(30):7868-76.

21. Moriana R, Zhang Y, Mischnick P, Li J, Ek M. Thermal degradation behavior and kinetic analysis of spruce glucomannan and its methylated derivatives. Carbohyd Polym. 2014;106:60-70. https://doi.org/10.1016/j.carbpol.2014.01.086.

22. Doyle C. Kinetic analysis of thermogravimetric data. J Appl Polym Sci. 1961;5(15):285-92.

23. Doyle CD. Series approximations to the equation of thermogravimetric data. Nature. 1965;207(4994):290-1.

24. Galwey AK, Brown ME. Chapter 3 kinetic models for solid state reactions. In: Galwey AK, Brown ME, editors. Studies in physical and theoretical chemistry. New York: Elsevier; 1999. p. $75-115$.

25. Costes L, Laoutid F, Brohez S, Dubois P. Bio-based flame retardants: when nature meets fire protection. Mater Sci Eng R Rep. 2017;117:1-25. https://doi.org/10.1016/j.mser.2017.04.001.

26. Angelini S, Cerruti P, Immirzi B, Santagata G, Scarinzi G, Malinconico M. From biowaste to bioresource: effect of a lignocellulosic filler on the properties of poly(3-hydroxybutyrate). Int J Biol Macromol. 2014;71:163-73. https://doi.org/10.1016/j. ijbiomac.2014.07.038.

27. Meng XY, Ye L, Zhang XG, Tang PM, Tang JH, Ji X, et al. Effects of expandable graphite and ammonium polyphosphate on the flame-retardant and mechanical properties of rigid polyurethane foams. J Appl Polym Sci. 2009;114(2):853-63.

28. Saeed RM, Schlegel J, Castano C, Sawafta R. Uncertainty of thermal characterization of phase change material by differential scanning calorimetry analysis. Int $\mathrm{J}$ Eng Res Appl. 2016;5(1):405-12.

29. Aboulkas A, El harfi $\mathrm{K}$, El Bouadili A. Thermal degradation behaviors of polyethylene and polypropylene. Part I: pyrolysis kinetics and mechanisms. Energ Convers Manag. 2010;51(7):1363-9. https://doi.org/10.1016/j.enconman.2009.12. 017.

30. Woo Park J, Cheon OhS, Pyeong Lee H, Taik Kim H, Ok Yoo K. A kinetic analysis of thermal degradation of polymers using a dynamic method. Polym Degrad Stabil. 2000;67(3):535-40. https://doi.org/10.1016/S0141-3910(99)00155-X.

31. Burnham AK, Dinh L. A comparison of isoconversional and model-fitting approaches to kinetic parameter estimation and application predictions. J Therm Anal Calorim. 2007;89(2):479-90.

32. Vyazovkin S, Sbirrazzuoli N. Isoconversional kinetic analysis of thermally stimulated processes in polymers. Macromol Rapid Commun. 2006;27(18):1515-32. https://doi.org/10.1002/marc. 200600404

33. Wu W, Cai J, Liu R. Isoconversional kinetic analysis of distributed activation energy model processes for pyrolysis of solid fuels. Ind Eng Chem Res. 2013;52(40):14376-83. https://doi.org/ 10.1021/ie4021123.

34. Heydari M, Rahman M, Gupta R. Kinetic study and thermal decomposition behavior of lignite coal. Int $\mathrm{J}$ Chem Eng. 2015;2015:1-9. https://doi.org/10.1155/2015/481739.

35. Liu X, Yu L, Xie F, Li M, Chen L, Li X. Kinetics and mechanism of thermal decomposition of cornstarches with different amylose/ amylopectin ratios. Starch-Stärke. 2010;62(3-4):139-46. https:// doi.org/10.1002/star.200900202.

36. Sun L, Wu Q, Xie Y, Song K, Lee S, Wang Q. Thermal decomposition of fire-retarded wood flour/polypropylene composites. J Therm Anal Calorim. 2015;123(1):309-18. https://doi. org/10.1007/s10973-015-4971-8.

37. Poletto M, Zattera AJ, Santana RM. Thermal decomposition of wood: kinetics and degradation mechanisms. Bioresour Technol. 2012;126:7-12. https://doi.org/10.1016/j.biortech.2012.08.133.

38. Poletto M. Assessment of the thermal behavior of lignins from softwood and hardwood species. Maderas Ciencia y Tecnología. 2017;19(1):63-74.

39. Poletto M, Pistor V, Zeni M, Zattera AJ. Crystalline properties and decomposition kinetics of cellulose fibers in wood pulp obtained by two pulping processes. Polym Degrad Stabil. 2011;96(4):679-85. https://doi.org/10.1016/j.polymdegradstab. 2010.12.007.

40. Wu Y, Dollimore D. Kinetic studies of thermal degradation of natural cellulosic materials. Thermochim Acta. 1998;324(1):49-57. https://doi.org/10.1016/S00406031(98)00522-X.

41. Brinchi L, Cotana F, Fortunati E, Kenny JM. Production of nanocrystalline cellulose from lignocellulosic biomass: technology and applications. Carbohyd Polym. 2013;94(1):154-69. https://doi.org/10.1016/j.carbpol.2013.01.033.

42. Shen D, Zhang L, Xue J, Guan S, Liu Q, Xiao R. Thermal degradation of xylan-based hemicellulose under oxidative atmosphere. Carbohyd Polym. 2015;127(Supplement C):363-71. https://doi.org/10.1016/j.carbpol.2015.03.067.

43. Yin J, Yuan T, Lu Y, Song K, Li H, Zhao G, et al. Effect of compression combined with steam treatment on the porosity, chemical compositon and cellulose crystalline structure of wood cell walls. Carbohyd Polym. 2017;155(Supplement C):163-72. https://doi.org/10.1016/j.carbpol.2016.08.013.

44. Wang S, Dai G, Yang H, Luo Z. Lignocellulosic biomass pyrolysis mechanism: a state-of-the-art review. Prog Energ Combust. 2017;62:33-86.

45. Lu Q, Zhang Y, Dong C, Yang Y, Yu H. The mechanism for the formation of levoglucosenone during pyrolysis of $\beta$-d-glucopyranose and cellobiose: a density functional theory study. J Anal Appl Pyrol. 2014;110:34-43.

46. Ma Z, Custodis V, van Bokhoven JA. Selective deoxygenation of lignin during catalytic fast pyrolysis. Catal Sci Technol. 2014;4(3):766-72.

47. Collard F-X, Blin J, Bensakhria A, Valette J. Influence of impregnated metal on the pyrolysis conversion of biomass 
constituents. J Anal Appl Pyrol. 2012;95(Supplement C):213-26. https://doi.org/10.1016/j.jaap.2012.02.009.

48. Stefanidis S, Kalogiannis K, Iliopoulou E, Lappas A, Pilavachi P. In-situ upgrading of biomass pyrolysis vapors: catalyst screening on a fixed bed reactor. Bioresour Technol. 2011;102(17):8261-7.

49. Lu Q, Dong C, Zhang X, Tian H, Yang Y, Zhu X. Selective fast pyrolysis of biomass impregnated with $\mathrm{ZnCl}_{2}$ to produce furfural: analytical Py-GC/MS study. J Anal Appl Pyrol. 2011;90(2):204-12. https://doi.org/10.1016/j.jaap.2010.12.007.

50. Wang S, Ru B, Lin H, Luo Z. Degradation mechanism of monosaccharides and xylan under pyrolytic conditions with theoretic modeling on the energy profiles. Bioresour Technol. 2013;143(Supplement C)):378-83. https://doi.org/10.1016/j.bior tech.2013.06.026.
51. Dupretz R, Fontaine G, Bourbigot S. Fire retardancy of a new polypropylene-grafted starch: part II: investigation of mechanisms. J Fire Sci. 2013;32(3):210-29. https://doi.org/10.1177/ 0734904113508725.

52. Czégény Z, Jakab E, Blazsó M. Pyrolysis of wood, cellulose, lignin-brominated epoxy oligomer flame retardant mixtures. J Anal Appl Pyrol. 2013;103:52-9. https://doi.org/10.1016/j.jaap. 2012.11.002.

53. Pappa A, Mikedi K, Tzamtzis N, Statheropoulos M. TG-MS analysis for studying the effects of fire retardants on the pyrolysis of pine-needles and their components. J Therm Anal Calorim. 2006;84(3):655-61. 